\title{
A comparative study of the Au-catalyzed cyclization of hydroxy-substituted allylic alcohols and ethers
}

\author{
Berenger Biannic, Thomas Ghebreghiorgis and Aaron Aponick ${ }^{*}$
}

\section{Full Research Paper}

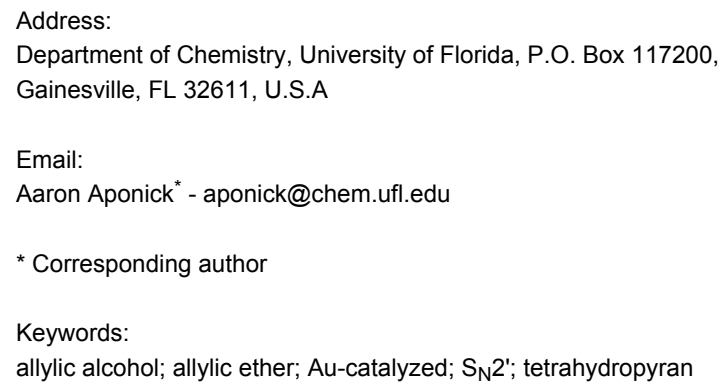

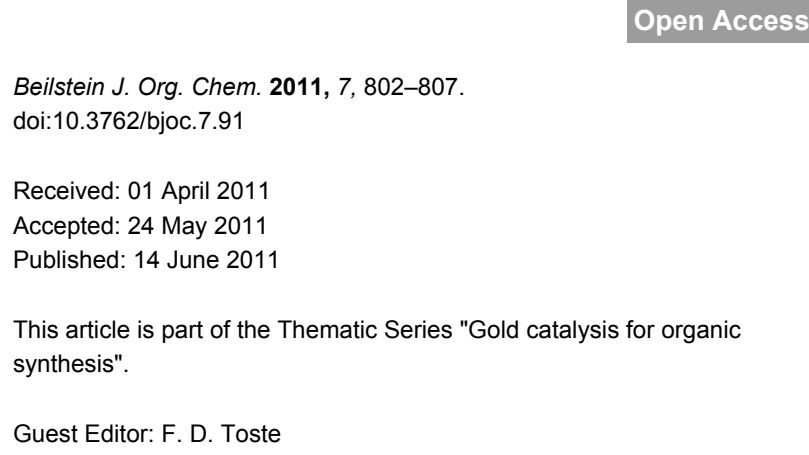

Beilstein J. Org. Chem. 2011, 7, 802-807. doi:10.3762/bjoc.7.91

Received: 01 April 2011

Accepted: 24 May 2011

Published: 14 June 2011

This article is part of the Thematic Series "Gold catalysis for organic synthesis".

Guest Editor: F. D. Toste

(C) 2011 Biannic et al; licensee Beilstein-Institut.

License and terms: see end of document.

\begin{abstract}
The $\mathrm{Au}(\mathrm{I})$-catalyzed cyclization of hydroxyallylic ethers to form tetrahydropyrans is reported. Employing (acetonitrile)[(obiphenyl)di-tert-butylphosphine]gold(I) hexafluoroantimonate, the cyclization reactions were complete within minutes to hours, depending on the substrate. The reaction progress was monitored by GC, and comparisons between substrates demonstrate that reactions of allylic alcohols are faster than the corresponding ethers. Additionally, it is reported that Reaxa QuadraPure ${ }^{\mathrm{TM}}$ MPA is an efficient scavenging reagent that halts the reaction progress.
\end{abstract}

\section{Introduction}

Saturated oxygen heterocycles are found in a wide variety of biologically interesting and structurally complex natural products [1]. These compounds are typically densely functionalized and contain numerous stereogenic centers. Many challenges for the total synthesis of these molecules revolve around issues of selectivity and can be complicated by the presence of sensitive functional groups. While cyclization reactions of highly elaborated substrates are desirable, mild chemoselective methods are necessary for this endeavor.

Homogeneous gold-catalyzed reactions have emerged as a powerful new methodology for the construction of a diverse array of molecular architectures; for recent reviews on Au-catal- ysis, see [2-10]. Generally, only mild conditions are necessary and these processes are highly chemoselective. While the typical substrates employed in these reactions effect transformations on alkyne, allene, and alkene moieties, recent reports from our laboratory and others have demonstrated that unsaturated alcohols, such as allylic and propargylic alcohols, are reactive substrates that readily participate in dehydrative formal $\mathrm{S}_{\mathrm{N}} 2^{\prime}$ reactions [11-25]. The formation of tetrahydropyrans is easily accomplished with monoallylic diol substrates, as illustrated in Scheme 1 [23-25]. The reactions are generally rapid and high yielding with low catalyst loading and can be carried out at low reaction temperatures. Additionally, they are stereospecific, as changing the olefin geometry provides enantiomeric products 
(Scheme 1, reaction 1 versus reaction 2) [25], and they are also tolerant of highly substituted substrates (Scheme 1, reaction 3) [23].

Although these features are attractive from a synthetic point of view, one potential disadvantage is that both the nucleophile and electrophile are alcohols that may require the introduction and cleavage of protecting groups in the preparation of more complex substrates. In the course of a synthetic project, we required a monoallylic diol but encountered difficulty due to an errant protecting group scheme. It was surmised that the problem would be solved if the allylic alcohol leaving group did not need to be revealed directly before the cyclization event. This led us to consider the use of alternative substrates where the allylic alcohol could be deprotected under the reaction conditions, or the use of other "protecting groups" that would also serve as leaving groups and obviate the need for a separate deprotection step. We reasoned that the best group to introduce would be one that was not susceptible to cleavage by standard deprotection conditions and therefore would only be removed after the desired cyclization reaction. Since alcohols are usually very poor leaving groups, but function extremely well in the present system, it seemed likely that a fairly robust group could perform satisfactorily here. Additionally, calculations suggest that in intermolecular hydroalkoxylation reactions of allenes the kinetic allylic ether products are isomerized by $\mathrm{Au}(\mathrm{I})-\mathrm{NHC}$ complexes to the regioisomeric thermodynamic (and observed) products [26]. Successful implementation of such a strategy would offer an alternative to the use of the highly successful and well-established set of leaving groups employed in $\pi$-allylmetal chemistry [27-32]. Herein we report a study of
Au-catalyzed cyclizations with different leaving groups that do not require deprotection, and data on the reaction progress that allows comparison between leaving groups and cis- versus trans-olefins.

\section{Results and Discussion}

At the outset, one of the important goals was to be able to make comparisons between how well different substrates function in the reaction. Previous papers detail the results with diols and include a variety of substrates with yields and reaction times [23-25]. While the isolated yield is the ultimate measure of how well the system has performed, these data do not provide sufficient details to compare accurately between different classes of substrates. We also sought to gain more insight into how fast the reaction proceeds and to be able to comment on catalyst lifetime.

To be consistent, we chose to study the simple system shown in Scheme 2 and to vary the nature of the allylic leaving group and olefin geometry. These conditions are slightly different to those employed in the study of diols [23-25], differing in catalyst identity and loading $\left(1 \mathrm{~mol} \%\left(\mathrm{Ph}_{3} \mathrm{P}\right) \mathrm{AuCl} / \mathrm{AgOTf}\right.$ versus $5 \mathrm{~mol} \% \mathrm{Au}\left[\mathrm{P}(t-\mathrm{Bu})_{2}(o\right.$-biphenyl $\left.\left.)\right] \mathrm{SbF}_{6}\right)$.

As mentioned above, the ability to follow the reaction progress was desired but this presented several practical challenges. As the reactions are often complete within minutes, a continuous method of analysis would be necessary, or alternatively samples could be collected over the course of the reaction with analysis to follow. Initial experiments focused on using ${ }^{1} \mathrm{H}$ NMR, but this raised concerns due to the heterogeneous nature of the reac-<smiles>OCCCC/C=C\C(O)CCc1ccccc1</smiles><smiles>OCCCCC=CC(O)CCc1ccccc1</smiles>

$3(96 \%$ ee)

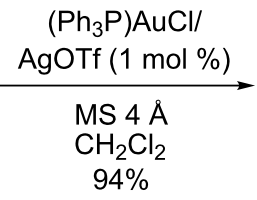

$\left(\mathrm{Ph}_{3} \mathrm{P}\right) \mathrm{AuCl} /$

$\underset{\mathrm{MS} 4 \AA}{\stackrel{\operatorname{AgOTf}(1 \mathrm{~mol} \%)}{\mathrm{CH}_{2} \mathrm{Cl}_{2}}}$

$91 \%$

$\left(\mathrm{Ph}_{3} \mathrm{P}\right) \mathrm{AuCl} /$

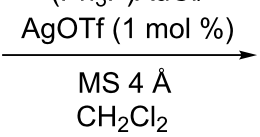

$89 \%$<smiles>C(=C/C1CCCCO1)\CCc1ccccc1</smiles>

$2(93 \%$ ee $)$<smiles>C(=C/C1CCCCO1)\CCc1ccccc1</smiles>

$4(93 \%$ ee $)$

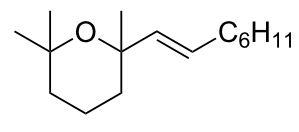

6 


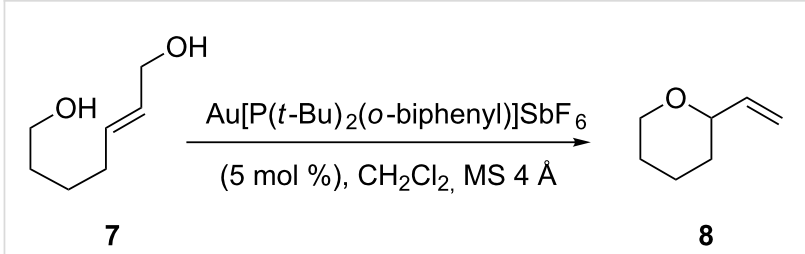

Scheme 2: Reaction conditions for the preparation of 8 .

tion mixture, which contained molecular sieves to absorb the water that was generated. Analysis by GC with decane as an internal standard was then explored. A standard curve was prepared with $\mathbf{8}$, but, due to the fact that Au-complexes are fairly stable in air and moisture, a quenching method was needed to obtain accurate results. In a typical experiment, the reaction is generally filtered through a short plug of silica, but for small aliquots $(25 \mu \mathrm{L})$ this was not practical. Instead the resin bound scavenging agent QuadraPure ${ }^{\mathrm{TM}}$ MPA 9 (Figure 1) was employed.

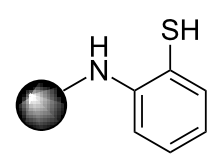

9

Figure 1: QuadraPure ${ }^{\mathrm{TM}}$ MPA.

To the best of our knowledge, scavenging reagents such as this have not previously been employed in homogeneous Au-catalysis and it was necessary to validate this method. In a typical reaction, the goal was to quench aliquots by injecting them into vials containing 9 suspended in $\mathrm{CH}_{2} \mathrm{Cl}_{2}$. For a detailed protocol see the Supporting Information File 1. As a test, samples were continually taken from the reaction illustrated in Scheme 2 and treated with 9 until TLC analysis indicated that the reaction was complete. GC analysis of the samples provided the data used to construct the black curve shown in Figure 2, which shows the expected behavior and was reproducible. As a control experiment, a sample taken after 3 minutes was diluted with $\mathrm{CH}_{2} \mathrm{Cl}_{2}$, but not exposed to the resin. After $16 \mathrm{~h}$, the reaction had proceeded to $95 \%$ conversion demonstrating that 9 is necessary to halt the progress of the reaction. The precision of the analysis also warrants comment. At several points throughout the reaction, the same sample was analyzed 5 times. In each of these sample sets, the range of percent conversion spanned approximately $2 \%$. The standard deviation from the mean was $0.92 \%$.

Figure 2 also demonstrates that the reactions can be quenched with QuadraPure ${ }^{\mathrm{TM}}$ MPA. The curves in red, green, and blue show the results of reactions that were quenched after 1,3 , and

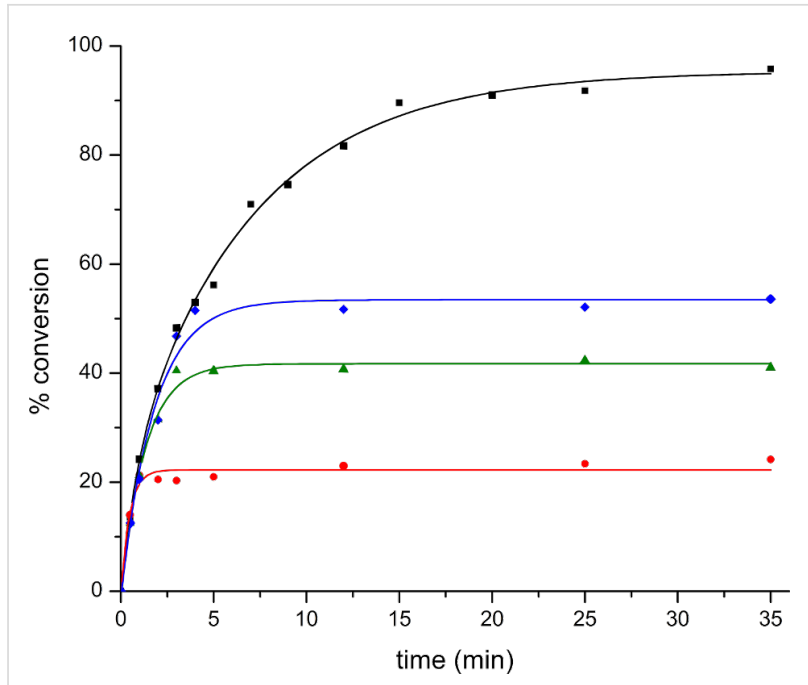

Figure 2: Quenching experiments using 9. = quenched after $1 \mathrm{~min}$; $\Delta$ = quenched after $3 \mathrm{~min} ; \bullet=$ quenched after $5 \mathrm{~min}$.

5 minutes, respectively. The reaction conditions were otherwise identical to the reaction shown in black, which proceeded to $96 \%$ conversion, while the reactions quenched at 1,3 , and 5 minutes went to $23 \%, 41 \%$, and $52 \%$ conversion, respectively.

Subsequently, a comparison between cis- and trans-diols $\mathbf{1 0}$ and 7 was made. As can be seen in Figure 3, both reactions were fairly rapid, with the cis-diol $\mathbf{1 0}$ being only slightly faster in the

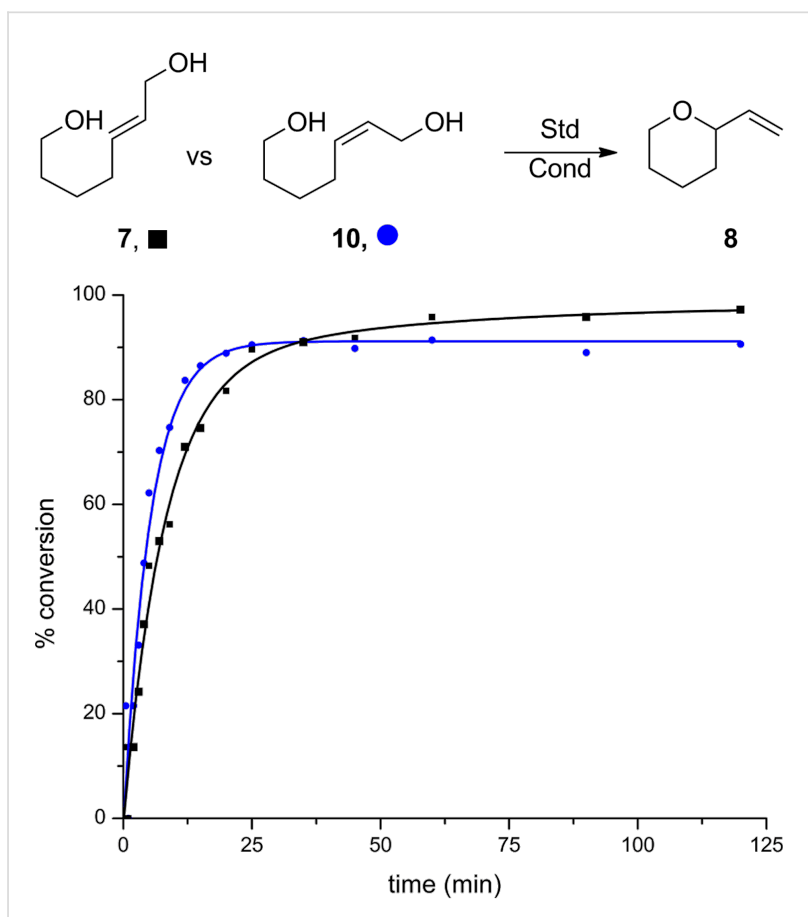

Figure 3: Reaction progress in cis- and trans-diols. Conditions: $5 \mathrm{~mol} \% \mathrm{Au}\left[\mathrm{P}(t-\mathrm{Bu})_{2}\right.$ (o-biphenyl)]SbF${ }_{6}, \mathrm{CH}_{2} \mathrm{Cl}_{2}, \mathrm{MS} 4 \AA$. 
initial period than 7. Interestingly, the reaction of 7 achieves higher conversion overall, but both substrates have $>90 \%$ conversion after 25 minutes.

The methyl ethers $\mathbf{1 1}$ and $\mathbf{1 2}$ were explored and proved to be suitable substrates (Figure 4). While these reactions were slightly slower in the initial stages than the corresponding diols, excellent conversions were achieved. This demonstrates that methyl ethers fit the criteria described above. The methyl group efficiently shields this functional group under a variety of commonly used conditions and it can then act as a leaving group under Au-catalyzed cyclization conditions.
11 ,<smiles>[M]OC/C=C/CCCCO</smiles><smiles>COC/C=C\CCCCO</smiles>

12,

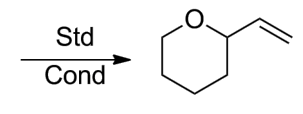

8

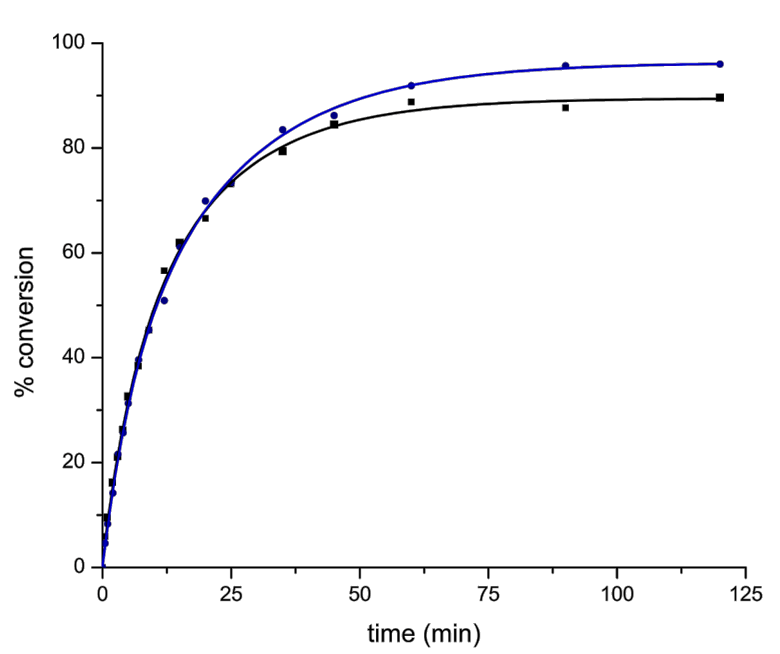

Figure 4: Reaction progress in cis- and trans-methyl ethers. Conditions: $5 \mathrm{~mol} \% \mathrm{Au}\left[\mathrm{P}(t-\mathrm{Bu})_{2}\right.$ (o-biphenyl) $\mathrm{SbF}_{6}, \mathrm{CH}_{2} \mathrm{Cl}_{2}, \mathrm{MS} 4 \AA$.

Several additional, commonly used, protecting groups were also screened under the reaction conditions (Figure 5). From the graph, it is apparent that benzyl (13), TBDPS (14), and THP [33] (15) could all be used, but esters such as benzoyl (16) were unsuitable. This may provide a basis for chemoselective transformations, as allyl esters are readily ionized by $\mathrm{Pd}^{0}$ complexes and the resulting $\pi$-allylpalladium species are alkylated by a variety of nucleophiles [27,28].

Finally, $1^{\circ}$ allylic and $2^{\circ}$ allylic ether substrates were compared (Figure 6). Substitution at the allylic position drastically slows the reaction. Although the conversion of $\mathbf{1 7}$ and $\mathbf{1 8}$ is low on the timescale shown, the reactions continue and after $48 \mathrm{~h}$ provide acceptable, but moderate yields. The corresponding trans- and

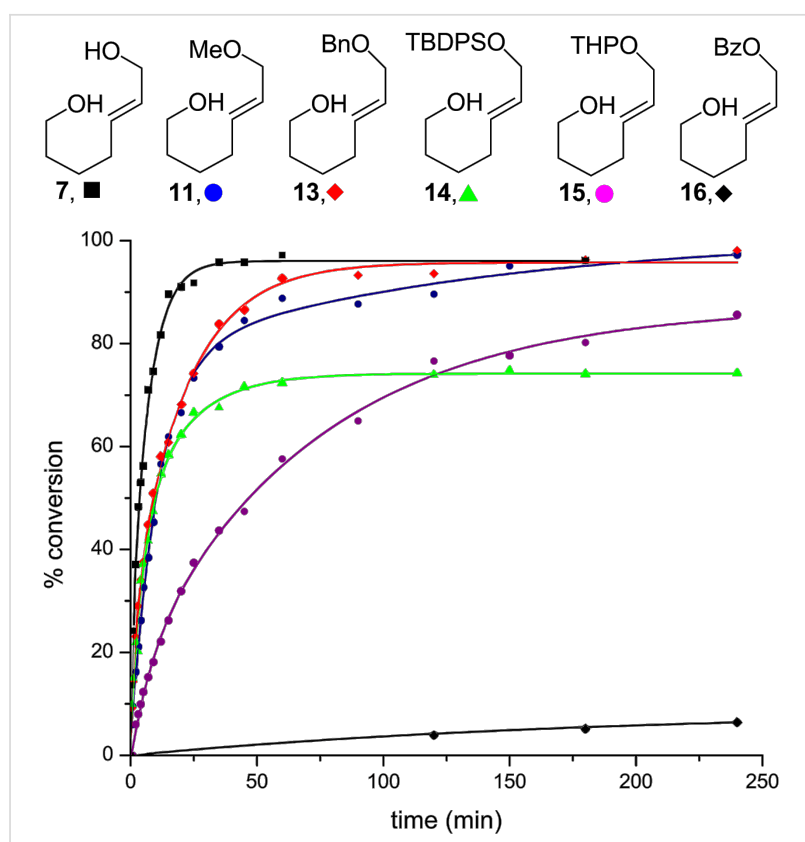

Figure 5: A comparison of commonly used protecting groups. Conditions: $5 \mathrm{~mol} \% \mathrm{Au}\left[\mathrm{P}(t-\mathrm{Bu})_{2}\right.$ (o-biphenyl) $] \mathrm{SbF}_{6}, \mathrm{CH}_{2} \mathrm{Cl}_{2}, \mathrm{MS} 4 \AA$.

cis-cyclohexyl-substituted diols (not shown) provide the products in $96 \%$ and $92 \%$ isolated yields after 40 minutes, respectively [23-25]. While cyclohexyl substituents significantly slow the reaction, it is likely that other less sterically demanding substituents will be better tolerated. This is currently under investigation with more synthetically useful substrates.

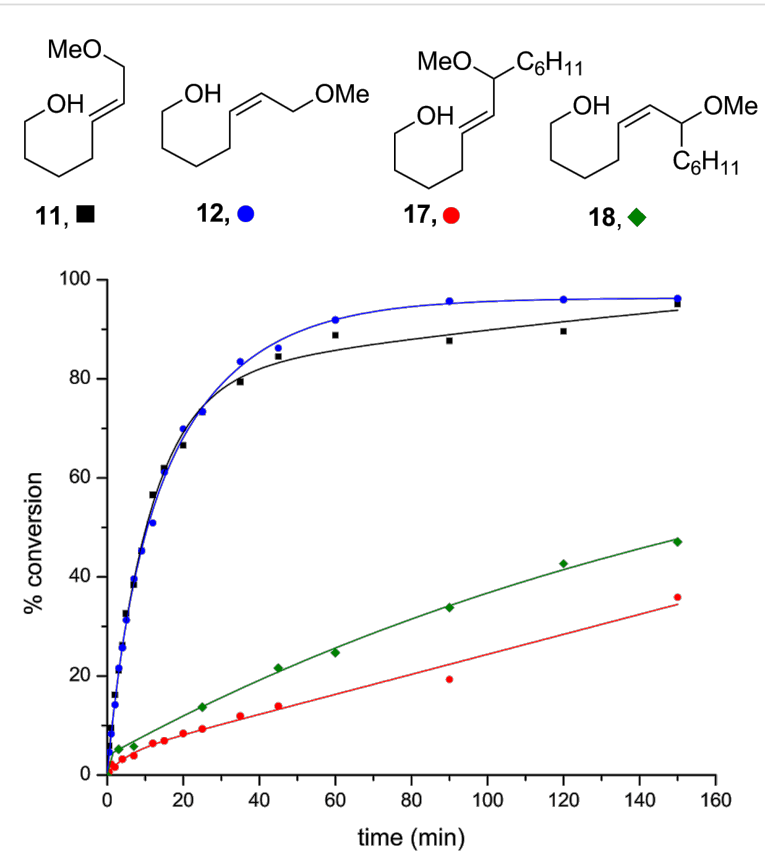

Figure 6: Comparison of $1^{\circ}$ and $2^{\circ}$ allylic ethers. Conditions: $5 \mathrm{~mol} \%$ $\mathrm{Au}\left[\mathrm{P}(t-\mathrm{Bu})_{2}\right.$ (o-biphenyl) $] \mathrm{SbF}_{6}, \mathrm{CH}_{2} \mathrm{Cl}_{2}, \mathrm{MS} 4 \AA$. 


\section{Conclusion}

In conclusion, it has been demonstrated that a variety of allylic ethers undergo Au-catalyzed formal $\mathrm{S}_{\mathrm{N}} 2$ ' reactions to form tetrahydropyrans. The reaction of allylic alcohols appears to be faster, although the leaving group is traditionally not considered to be as good. Reactions of cis-substrates appear to be slightly faster than the corresponding trans-allylic ethers. While the difference is small, it suggests that it is better to prepare the cis-substrates, and this is also very straightforward via a number of different routes. Further studies on secondary allylic ethers and on the application of the method in total synthesis are ongoing and will be reported in due course.

\section{Supporting Information}

\section{Supporting Information File 1}

General procedures and characterization data for all new compounds.

[http://www.beilstein-journals.org/bjoc/content/ supplementary/1860-5397-7-91-S1.pdf]

\section{Acknowledgements}

We gratefully acknowledge the Florida Department of Health, James and Ester King Biomedical Research Program for funding of this work (09-KN-01-23124). We thank Petra Research, Inc. for the gift of starting materials and an unrestricted research award and Prof. Jon Stewart (UF) for assistance with the GC analysis.

\section{References}

1. Blunt, J. W.; Copp, B. R.; Munro, M. H. G.; Northcote, P. T.; Prinsep, M. R. Nat. Prod. Rep. 2010, 27, 165-237. doi:10.1039/B906091J

2. Hashmi, A. S. K.; Bührle, M. Aldrichimica Acta 2010, 43, 27-33.

3. Hashmi, A. S. K. Angew. Chem., Int. Ed. 2010, 49, 5232-5241. doi:10.1002/anie.200907078

4. Shapiro, N. D.; Toste, F. D. Synlett 2010, 675-691. doi:10.1055/s-0029-1219369

5. Hashmi, A. S. K.; Rudolph, M. Chem. Soc. Rev. 2008, 37, 1766-1775. doi:10.1039/b615629k

6. Li, Z.; Brouwer, C.; He, C. Chem. Rev. 2008, 108, 3239-3265. doi:10.1021/cr068434l

7. Arcadi, A. Chem. Rev. 2008, 108, 3266-3325. doi:10.1021/cr068435d

8. Gorin, D. J.; Sherry, B. D.; Toste, F. D. Chem. Rev. 2008, 108, 3351-3378. doi:10.1021/cr068430g

9. Muzart, J. Tetrahedron 2008, 64, 5815-5849. doi:10.1016/j.tet.2008.04.018

10. Shen, H. C. Tetrahedron 2008, 64, 3885-3903. doi:10.1016/j.tet.2008.01.081

11. Mukherjee, P.; Widenhoefer, R. A. Org. Lett. 2011, 13, 1334-1337. doi:10.1021/ol103175w

12. Aponick, A.; Li, C.-Y.; Palmes, J. A. Org. Lett. 2009, 11, 121-124. doi:10.1021/ol802491m
13. Aponick, A.; Li, C.-Y.; Malinge, J.; Marques, E. F. Org. Lett. 2009, 11, 4624-4627. doi:10.1021/ol901901m

14. Mukherjee, P.; Widenhoefer, R. A. Org. Lett. 2010, 12, 1184-1187. doi:10.1021/ol902923e

15. Bandini, M.; Eichholzer, A. Angew. Chem., Int. Ed. 2009, 48, 9533-9537. doi:10.1002/anie.200904388

16. Lu, Y.; Fu, X.; Chen, H.; Du, X.; Jia, X.; Liu, Y. Adv. Synth. Catal. 2009, 351, 129-134. doi:10.1002/adsc.200800490

17. Shu, X.-Z.; Liu, X.-Y.; Xiao, H.-Q.; Ji, K.-G.; Guo, L.-N.; Liang, Y.-M. Adv. Synth. Catal. 2008, 350, 243-248. doi:10.1002/adsc.200700452

18. Guo, S.; Song, F.; Liu, Y. Synlett 2007, 964-968. doi:10.1055/s-2007-973865

19. Georgy, J.; Boucard, V.; Debleds, O.; Dal Zotto, C.; Campagne, J.-M. Tetrahedron 2009, 65, 1758-1766. doi:10.1016/j.tet.2008.12.051

20. Kothandaraman, P.; Foo, S. J.; Chan, P. W. H. J. Org. Chem. 2009, 74, 5947-5952. doi:10.1021/jo900917q

21. Aponick, A.; Biannic, B.; Jong, M. R. Chem. Commun. 2010, 46, 6849-6851. doi:10.1039/c0cc01961e

22. Bandini, M.; Monari, M.; Romaniello, A.; Tragni, M. Chem.-Eur. J. 2010, 16, 14272-14277. doi:10.1002/chem.201002606

23. Aponick, A.; Li, C.-Y.; Biannic, B. Org. Lett. 2008, 10, 669-671. doi:10.1021/ol703002p

24. Aponick, A.; Biannic, B. Synthesis 2008, 3356-3359. doi:10.1055/s-0028-1083160

25. Aponick, A.; Biannic, B. Org. Lett. 2011, 13, 1330-1333. doi:10.1021/ol200203k

26. Paton, R. S.; Maseras, F. Org. Lett. 2009, 11, 2237-2240. doi:10.1021/ol9004646

27. Tsuji, J. The Tsuji-Trost Reaction and Related Carbon-Carbon Bond Formation Reactions: Overview of the Palladium-Catalyzed Carbon-Carbon Bond Formation via m-Allylpalladium and Propargylpalladium Intermediates. In Handbook of Organopalladium Chemistry for Organic Synthesis; Negishi, E.-i.; de Meijere, A., Eds.; Wiley Interscience: New York, 2002; Vol. 2, pp 1669-1687. doi:10.1002/0471212466.ch70

28. Trost, B. M.; Crawley, M. L. Chem. Rev. 2003, 103, 2921-2944. doi:10.1021/cr020027w

29. Gruber, S.; Pregosin, P. S. Adv. Synth. Catal. 2009, 351, 3225-3242. doi:10.1002/adsc.200900568

30. Tanaka, S.; Saburi, H.; Kitamura, M. Adv. Synth. Catal. 2006, 348, 375-378. doi:10.1002/adsc.200505401

31. Saburi, H.; Tanaka, S.; Kitamura, M. Angew. Chem., Int. Ed. 2005, 44, 1730-1732. doi:10.1002/anie.200462513

32. Tanaka, S.; Saburi, H.; Ishibashi, Y.; Kitamura, M. Org. Lett. 2004, 6, 1873-1875. doi:10.1021/ol0493397

33. Miyazawa, M.; Hirose, Y.; Narantsetseg, M.; Yokoyama, H.; Yamagushi, S.; Hirai, Y. Tetrahedron Lett. 2004, 45, 2883-2886. doi:10.1016/j.tetlet.2004.02.058 


\section{License and Terms}

This is an Open Access article under the terms of the Creative Commons Attribution License

(http://creativecommons.org/licenses/by/2.0), which permits unrestricted use, distribution, and reproduction in any medium, provided the original work is properly cited.

The license is subject to the Beilstein Journal of Organic Chemistry terms and conditions:

(http://www.beilstein-journals.org/bjoc)

The definitive version of this article is the electronic one which can be found at:

doi:10.3762/bjoc.7.91 